\title{
Bone Marrow-Derived Cells Implanted into Radiation-Injured Urinary Bladders Reconstruct Functional Bladder Tissues in Rats
}

\author{
Tetsuya Imamura, Ph.D., ${ }^{1}$ Osamu Ishizuka, M.D., Ph.D., ${ }^{1,2}$ Zhang Lei, Ph.D., ${ }^{2}$ Shigeaki Hida, Ph.D., ${ }^{3}$ \\ Gautam Silwal Sudha, B.Pharm., M.B.A., ${ }^{2}$ Haruaki Kato, M.D., Ph.D., ${ }^{2}$ and Osamu Nishizawa, M.D., Ph.D.,
}

The purpose of this study was to determine whether bone marrow-derived cells implanted into radiation-injured urinary bladders could reconstruct functional bladder tissues. The pelvic region of anesthetized female SpragueDawley (SD) rats was irradiated with 2 Gy once a week for 5 weeks. After the last irradiation, the rats were maintained for 2 weeks. Bone marrow cells were harvested from the femurs of donor male green fluorescence protein (GFP)-transfected SD rats and cultured for 7 days. Two weeks after the last radiation exposure, the cultured adherent, proliferating bone marrow-derived cells were implanted into the walls of irradiated urinary bladders. For controls, cell-free solutions were similarly injected. Four weeks after donor cell or control implantations, cystometric, histological, and immunohistochemical investigations were performed. Two weeks after the last irradiation, the smooth muscle layers and nerve fibers of the irradiated urinary bladders were disorganized. The proportions of smooth muscle layer and nerve fiber areas were significantly decreased compared with sham-irradiated urinary bladders. In addition, the remaining smooth muscle cells within the irradiated urinary bladders expressed $\mathrm{P} 4 \mathrm{HB}$, an indicator of collagen synthesis. In the cystometric investigations, the voiding interval of irradiated rats was irregularly prolonged, $7.92 \pm 1.09 \mathrm{~min}$, and the residual volume, $0.13 \pm 0.03 \mathrm{~mL}$, was significantly higher compared with the sham-irradiated rats $(5.50 \pm 0.43 \mathrm{~mL}$ and $0.05 \pm 0.01 \mathrm{~mL})$. After 4 weeks, the smooth muscle layers and nerve fibers in the cell-free control urinary bladders remained similar to the preimplanted irradiated urinary bladders; however, the cell-implanted urinary bladders contained reconstructed smooth muscle layers and nerve fibers, the proportions of each were significantly higher than those in the cell-free injected controls. The expression of P4HB within the cell-implanted urinary bladders decreased. Some GFPpositive implanted cells differentiated into smooth muscle- and nerve-like cells and became organized into the reconstructed tissues. The voiding interval of the cell-implanted rats, $5.46 \pm 0.33 \mathrm{~min}$, was regular and similar to that of the sham-irradiated rats, and significantly less than that of the cell-free injected controls, $7.39 \pm 0.54 \mathrm{~min}$. The residual volume, $0.04 \pm 0.01 \mathrm{~mL}$, was similar to that of the sham-irradiated rats and significantly decreased compared with that of the cell-free injected controls, $0.15 \pm 0.05 \mathrm{~mL}$. Therefore, the implantation of bone marrowderived cells is a potentially useful treatment for radiotherapy-induced urinary dysfunctions.

\section{Introduction}

$\mathbf{P}$ ELVIC RADIOTHERAPY IS AN EFFECTIVE and common treatment for a wide variety of malignancies localized in the rectum, uterus/cervix, prostate, and urinary bladder. Patients receiving pelvic radiotherapy often experience side effects due to the collateral damage of nearby organs. For instance, patients receiving pelvic radiotherapy complain about rectal disturbance, erectile dysfunction, ${ }^{1-4}$ and/or urinary dysfunction, ${ }^{5-9}$ which impair social interactions and reduce the quality of life. ${ }^{10-12}$ Recently, the relationship between the spatial distribution of the external beam during radiotherapy and the consequential dysfunction of normal organs has been investigated to try and avoid the side effects. ${ }^{13-16}$

The urinary bladder is one of the organs that is most often affected by the side effects of pelvic radiotherapy. Radiotherapy-induced urinary bladder damage has both acute and chronic phases. The acute phase is radiation-induced cystitis associated with inflammation within the bladder wall. This is accompanied by increased urinary frequency, dysuria, and urgency. ${ }^{17,18}$ The chronic phase develops 6 months to 20 years after the acute radiation-induced cystitis and can last

Departments of ${ }^{1}$ Lower Urinary Tract Medicine and ${ }^{2}$ Urology, Shinshu University School of Medicine, Nagano, Japan.

${ }^{3}$ Department of Molecular Oncology, Institute on Aging and Adaptation, Shinshu University Graduate School of Medicine, Nagano, Japan. 
for a lifetime. It is characterized by bladder wall vascular damage and/or fibrosis, followed by reduced bladder compliance and capacity. ${ }^{19,20}$ These changes are serious and irreversible, and there are only a few effective treatments. ${ }^{21-23}$

Earlier, we had shown that bone marrow-derived cells implanted into freeze-injured urinary bladders can reconstruct functional bladder tissues. ${ }^{24}$ Thus, the reconstruction and replacement of radiation-damaged bladder tissues have the potential to greatly improve bladder functions. In this study, we induced radiation damage to rat urinary bladders to produce a model that mimicked human radiotherapyinduced bladder dysfunction. We then investigated the ability of bone marrow-derived cells implanted into irradiated urinary bladders to reconstruct functional tissues.

\section{Materials and Methods}

\section{Animals}

Forty female 10-week-old Sprague-Dawley (SD) rats (Japan SLC Inc., Shizuoka, Japan) were sham irradiated or received urinary bladder irradiation followed by implantation of bone marrow-derived cells or control injections. Five male 17-week-old green fluorescence protein (GFP)-transfected Tg-SD rats (Japan SLC Inc.) were used as bone marrow cell donors. All animals were treated in accordance with the National Institutes of Animal Health Care Guidelines, and the guidelines were approved by the Animal Ethics Committee of the Shinshu University School of Medicine.

\section{Production of radiation-injured urinary bladder models}

Thirty female SD rats were anesthetized with a pentobarbital sodium solution $(40 \mathrm{mg} / \mathrm{kg}$-body weight; Abbott Laboratories, Abbott Park, IL) and secured in the supine position to a board. Subsequently, they were covered with an iron shield (Miyakoh Inc., Nagano, Japan) except for a 1-cm diameter circle bordering on the pubic bone to allow radiation of the pelvic region containing the urinary bladder (Fig. 1A). The exposed area was irradiated with 2 Gy once a week for 5 weeks, receiving a total of $10 \mathrm{~Gy}$, equivalent to an absorbed energy of $10 \mathrm{~J} / \mathrm{kg}$. After the last radiation exposure, the rats were maintained with freely available food and water under a 12-h alternating light-dark cycle for 2 weeks.

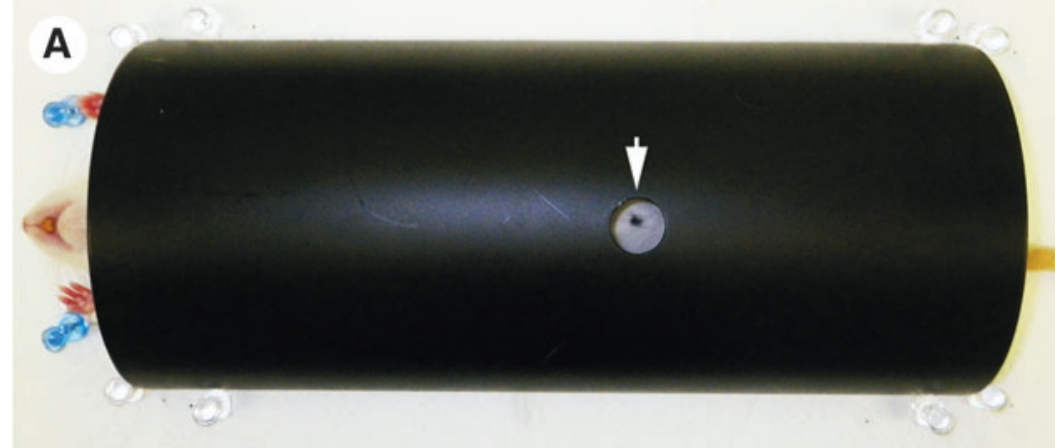

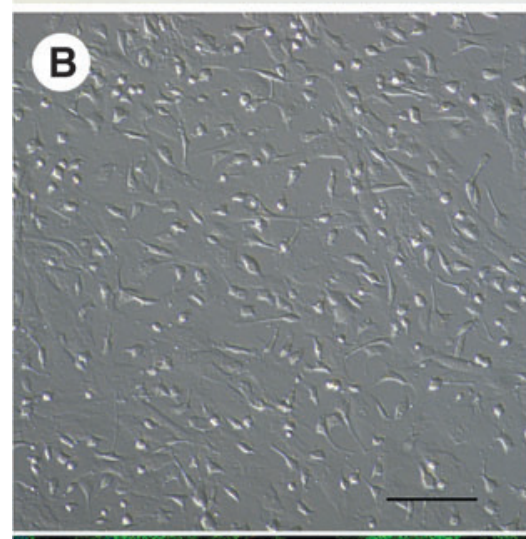
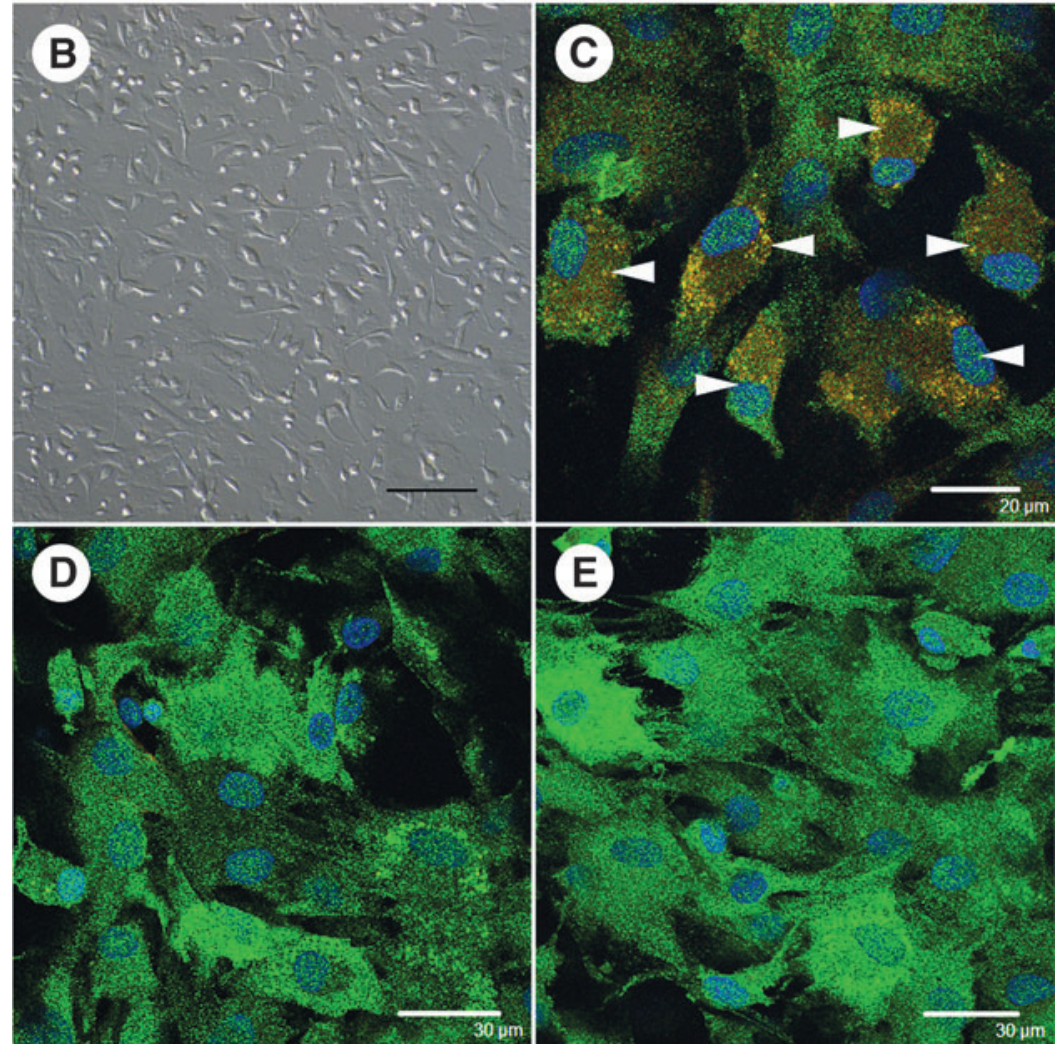

FIG. 1. Production of radiation-injured urinary bladders and cultured bone marrow-derived cells. (A) The pelvic region encompassing the urinary bladder (arrow) was irradiated with 2 Gy once a week for 5 weeks. (B) After 7 days of culture, the adherent, proliferating spindle-shaped bone marrow-derived cells were harvested and implanted in the radiation-injured bladders. Scale bar: $100 \mu \mathrm{m}$. (C) Just before implantation, the cultured cells expressed green fluorescence protein (GFP) (green), and they were positive for STRO1 (yellow, arrowheads). Blue: nuclei. Scale bar: $20 \mu \mathrm{m}$. (D, E) The cultured cells were negative for smooth muscle actin (SMA) (D) and S100 (E). Blue: nuclei. Scale bar: $30 \mu \mathrm{m}$. 
The irradiated rats were separated into a cell implantation group and a cell-free injection control group ( $n=10$ each). Ten other irradiated rats were used as a preimplantation group to determine the radiation-injured urinary bladders before cell implantation. Ten female SD rats that did not receive radiation exposure were used as a sham-irradiated group.

\section{Harvest and culture of bone marrow cells}

Five male Tg-SD rats were anesthetized with a pentobarbital sodium solution ( $50 \mathrm{mg} / \mathrm{kg}$-body weight; Abbott Laboratories). Both femurs of each rat were harvested and washed with saline. Both ends of the femurs were cut and flushed into a centrifuge tube using a 21-gauge needle on a syringe filled with $10 \mathrm{~mL}$ culture medium composed of Dulbecco's modified Eagle's medium (Gibco, Grand Island, NY) supplemented with $15 \%$ regular fetal bovine serum (Biowest, Nuaille, France) and $0.1 \%$ penicillin-streptomycin solution (Gibco). The harvested cell suspensions were filtered through $40-\mu \mathrm{m}$ nylon mesh filters (BD Biosciences, San Jose, CA) and then centrifuged at $1000 \mathrm{rpm}$ for $4 \mathrm{~min}$. The pellets were resuspended with $10 \mathrm{~mL}$ culture medium and inoculated into type I collagen-coated 10-cm culture dishes (Iwaki, Asahi Techno Glass, Chiba, Japan). The cells were incubated at $37^{\circ} \mathrm{C}$ in humid air with $5 \% \mathrm{CO}_{2}$ for 7 days. The medium was completely replaced every day, and nonattached cells were discarded. Seven days after culture, adherent proliferating bone marrow-derived cells were dissociated with $0.25 \%$ trypsin (Gibco) and suspended at $1.0 \times 10^{7}$ cells $/ \mathrm{mL}$ with a culture medium. These cells were then implanted into the irradiated urinary bladders as described next.

\section{Implantation of bone marrow-derived cells}

Two weeks after the last radiation treatment and 7 days after the bone marrow cell cultures had been initiated, the recipients were anesthetized with a pentobarbital sodium solution ( $40 \mathrm{mg} / \mathrm{kg}$-body weight; Abbott Laboratory), and the irradiated urinary bladders were exposed. For the cellimplantation group, $0.5 \times 10^{6}$ bone marrow-derived cells suspended in $50 \mu \mathrm{L}$ culture medium were implanted with a 29-gauge syringe at four different sites of the anterior and posterior bladder walls. The total implanted cells were $2.0 \times 10^{6}$. For the cell-free control group, $50 \mu \mathrm{L}$ of the culture medium was similarly injected. The implantation cell number and volume were carefully chosen to avoid further damage of the host tissues or sheer stress to the implanted cells. At each operation, the retention of small swellings formed with the implanted cells or control solutions was visually confirmed.

\section{Cystometric investigation}

Four weeks after the bone marrow-derived cell or control cell-free injections, we performed cystometric investigations. Two days before these studies, the animals were anesthetized with a pentobarbital sodium solution $(40 \mathrm{mg} / \mathrm{kg}$-body weight; Abbott Laboratory), and the urinary bladders were exposed and incised at the top. A polyethylene catheter (PE50; Nippon Becton Dickinson, Tokyo, Japan) was inserted through the incision and fixed at that site with 5-0 silk thread. The free end of the catheter was subcutaneously tu- nneled and exteriorized at the back of the neck. All the rats were individually maintained as just described. Cystometric investigations were performed on unanesthetized, unrestricted rats placed in a metabolic cage. The catheter inserted into the urinary bladder was connected via a T-tube to a pressure transducer (P23 DC; Statham, Oxnard, CA) and a syringe pump (Terumo Inc., Tokyo, Japan). The saline maintained at room temperature was instilled into the urinary bladder at a rate of $10 \mathrm{~mL} / \mathrm{h}$. Bladder contractions were recorded continuously on a pen oscillograph $(10 \mathrm{~mm} / \mathrm{min}$ recording speed, Recti-Horiz-8K; NEC San-ei Instruments, Tokyo, Japan). Micturition volume, measured with a fluid collector connected to force displacement transducer (Type 45196; NEC San-ei Instruments), was simultaneously recorded. The rats were not given food and water during the cystometric investigations. The following cystometric parameters were directly measured: basal, threshold, and micturition pressures $\left(\mathrm{cmH}_{2} \mathrm{O}\right)$; micturition volume $(\mathrm{mL})$; and voiding interval (minutes). Residual volume (mL) was calculated by subtracting the micturition volume from the saline infusion volume.

\section{Histological investigations}

After the cystometric investigations, the rats were anesthetized with a pentobarbital sodium solution $(50 \mathrm{mg} / \mathrm{kg}$ body weight; Abbott Laboratory). The urinary bladders were removed, and then, the animals were euthanized by the inhalation of diethyl ether. The tissue samples were fixed in $4 \%$ paraformaldehyde and $4 \%$ sucrose in $0.1 \mathrm{M}$ phosphate buf-

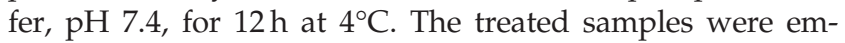
bedded in paraffin and cut into 5 - $\mu$ m-thick serial sections. The sections were deparaffinized, rehydrated, and rinsed with phosphate-buffered saline (PBS). The sections from each sample were stained with hematoxylin and eosin (HE), Masson trichrome, enzyme-labeled acethylcholinesterase antibody, or picrosirius red and then observed and photographed with a common optical microscope. HE staining was used to develop an overview of the whole tissue sample. The sections stained with Masson trichrome and acethylcholinesterase antibody were used, respectively, to semiquantitatively evaluate the proportion of smooth muscle layer and nerve fiber areas in each slide. The evaluations were conducted with image analysis software (Image-Pro ${ }^{\circledR}$ Plus, Media Cybernetics Inc., Bethesda, MD). Picrosirius red stain was used to observe collagen fibers (types I and III).

\section{Fluorescence double-label immunohistochemistry}

For immunohistochemistry, tissue serial sections were similarly deparaffinized, rehydrated, rinsed thrice with PBS, and then immersed in $10 \mathrm{mM}$ sodium citrate, $\mathrm{pH}$ 6.0. For antigen retrieval, the sections were microwaved at $100^{\circ} \mathrm{C}$ for $5 \mathrm{~min}$. The specimens were coated with $1.5 \%$ normal donkey serum (Chemicon International Inc., Temecula, CA) and $1.5 \%$ nonfat milk in PBS for $1 \mathrm{~h}$ at $4^{\circ} \mathrm{C}$.

To detect the implanted bone marrow-derived cells, the sections were incubated for $12 \mathrm{~h}$ at $4^{\circ} \mathrm{C}$ with GFP antibody (1:500, mouse monoclonal; Lifespan Biosciences, Inc., Seattle, WA). The sections were rinsed with PBS at $4^{\circ} \mathrm{C}$, and then incubated with secondary antibody consisting of donkey anti-mouse IgG conjugated with Alexa fluor 488 (1:250; Molecular Probes, Eugene, OR) for $1 \mathrm{~h}$ at $4^{\circ} \mathrm{C}$. 
After subsequent rinsing, the sections were then incubated for $12 \mathrm{~h}$ at $4^{\circ} \mathrm{C}$ with antibodies for alpha-smooth muscle actin (SMA, 1:100, mouse monoclonal; Progen Biotechnik GmbH, Heidelberg, Germany), desmin (1:50, rabbit monoclonal; Progen Biotechnik $\mathrm{GmbH}$ ), or calponin I (1:200, goat polyclonal; Santa Cruz Biotechnology Inc., Santa Cruz, CA) as markers for smooth muscle cells. Alternatively, they were incubated with antibodies for S100 (1:50, mouse monoclonal; Abcom, Cambridge, United Kingdom), tubulin beta 3 (1:50, rabbit monoclonal; Novus Biologicals, Inc., Littleton, CO), or calcitonin gene-related peptide (CGRP, 1:500, guinea pig polyclonal; Progen Biotechnik $\mathrm{GmbH}$ ) as markers for nerve cells. The sections were rinsed with PBS at $4^{\circ} \mathrm{C}$, and then incubated with secondary antibody consisting of donkey anti-mouse, anti-rabbit, anti-goat, or anti-guinea pig IgG conjugated with Alexa fluor 594 (1:250; Molecular Probes) for $1 \mathrm{~h}$ at $4^{\circ} \mathrm{C}$. After rinsing, the nuclei were counterstained with 4',6-diamidino-2-phenylindole dihydrochloride (DAPI, $5 \mu \mathrm{g} / \mathrm{mL}$; Molecular Probes), and then coated with Fluorescent Mounting Medium (Dako Cytomation, Carpinteria, CA). Other samples were similarly stained with SMA and collagen prolyl 4-hydroxylase beta (P4HB, 1:50, mouse monoclonal; Novus Biologicals, Inc.). P4HB plays an essential role in the synthesis of all collagens. In addition, cultured bone marrow-derived cells were similarly double stained with GFP and the mesenchymal cell marker STRO-1 (CD34, 1:100, R\&D System Inc., Minneapolis, MN), SMA, or S100, as just described. The slides were observed and photographed with a Leica DAS Microscopethe (Leica Microsystems $\mathrm{GmbH}$, Wetzlar, Germany).

\section{Statistical analysis}

Results were expressed as means \pm standard deviation. Statistical differences were determined using the Excel ${ }^{\circledR}$ Statistics program (Esumi Co., Ltd. Tokyo, Japan). Nonrepeated measures analysis of variance was followed by the Scheff's test. Differences with $p<0.05$ were considered significant.

\section{Results}

In preliminary studies, we confirmed that a higher than 10 Gy irradiation induced a $10 \%$ or more decrease in body weight, or, in some cases, death of the experimental animals. The $10 \%$ loss was established as a cut-off point by the Animal Ethics Committee of the Shinshu University School of Medicine. During this study, the body weight of the recipient rats irradiated with a total of $10 \mathrm{~Gy}$ did not decrease. Before cell implantation, the body weights of the cell implantation group and the cell-free control group were $252.1 \pm 2.5 \mathrm{~g}$ and $250.1 \pm 3.6 \mathrm{~g}$, respectively. At 4 weeks after implantation, the body weight of the cell-implanted rats, $264.4 \pm 3.8 \mathrm{~g}$, was significantly higher than that of the cell-free injected controls, $255.0 \pm 2.8 \mathrm{~g}(p<0.05)$.

\section{Bone marrow-derived cells}

Immediately after plating in collagen-coated culture dishes, the harvested Tg-SD bone marrow cells consisted of heterogeneous, spindle-shaped, round, and polygonal cells along with red blood cells. Seven days after culture, the adhered proliferating cells were nearly confluent, and they exhibited a relatively uniform, spindle-shaped morphology (Fig. 1B). The cultured cells were positive for STRO1, a mesenchymal cell marker, as well as for GFP (Fig. 1C). However, the cells were positive for neither the smooth muscle cell marker SMA (Fig. 1D) nor the nerve cell marker S100 (Fig. 1E).

\section{Histoarchitecture of radiation-injured urinary bladders}

Two weeks after the last irradiation and before donor cell implantation, we histologically examined the sham and radiation-exposed urinary bladders. To the naked eye, the sham-irradiated bladder walls were pinker due to distinct blood vessels (Fig. 2A inset) that were more prominent than those in the paler walls of the irradiated urinary bladders (Fig. 2C, inset). Staining by HE (Fig. 2A) and Masson trichrome (Fig. 2B) showed that the sham-irradiated urinary bladders had thick smooth muscle layers composed of numerous smooth muscle cells. In contrast, the smooth muscle layers within the irradiated, preimplanted urinary bladders were disorganized (Fig. 2C, D). The proportion of smooth muscle area in the sham-irradiated urinary bladders, $0.20 \pm 0.01$, was significantly higher than that in the preimplanted irradiated ones, $0.08 \pm 0.01(p<0.05$, Table 1$)$.

The sham-irradiated urinary bladders had distinct and numerous nerve fibers that were positive for acethylcholinesterase (Fig. 2E). In contrast, the preimplanted irradiated urinary bladders had a few acethylcholinesterase-positive nerve fibers (Fig. 2F). The proportion of nerve fiber area in the sham-irradiated urinary bladders, $0.12 \pm 0.03$ (Table 1), was also significantly higher than that in the preimplanted irradiated ones, $0.03 \pm 0.01 \quad(p<0.01$, Table 1$)$. As observed in picrosirious red staining, collagen fibers of the shamirradiated urinary bladders were placed among the smooth muscle layers (Fig. 2G), and the smooth muscle cells within the layers were negative for P4HB (Fig. 2G inset), an enzyme that is essential for the synthesis of collagen. In the preimplanted irradiated urinary bladders, collagen fibers were largely absent except where they accumulated together in clusters (Fig. 2H). In those regions, the remaining smooth muscle cells expressed $\mathrm{P} 4 \mathrm{HB}$ (Fig. 2H inset).

\section{Histoarchitecture of reconstructed radiation-injured urinary bladders}

Four weeks after the cell-free control injection, the bladder walls were similar to those in the preimplanted irradiated ones (Fig. 3A, inset). In contrast, the 4-week cell-implanted bladder walls had distinct, thick blood vessels (Fig. 3C inset) that were similar to the sham-irradiated ones. Staining by HE (Fig. 3A) and Masson trichrome (Fig. 3B) showed that the control cell-free injected urinary bladders had a few layered structures which were not typical smooth muscle layers. The cell-implanted urinary bladders had thick and typical smooth muscle layers that were composed of numerous smooth muscle cells (Fig. 3C, D). In addition, there were some blood vessels within the reconstructed layers (Fig. 3D). The cell-implanted urinary bladders had GFP-positive donor cells (Fig. 3D inset).

The proportion of smooth muscle layer area in the cellimplanted urinary bladders, $0.19 \pm 0.01$, was significantly higher than that in the cell-free injected control urinary bladders, $0.11 \pm 0.004(p<0.05$, Table 1$)$. The cell-free injected 
FIG. 2. Histoarchitecture of the preimplanted urinary bladders. (A-D) The sham-irradiated bladder walls had distinct blood vessels ( $\mathbf{A}$, inset); however, 2 weeks after the last irradiation, the preimplanted bladder walls were pale (C, inset). The shamirradiated urinary bladders had thick smooth muscle layers composed of numerous smooth muscle cells (A, arrows). The smooth muscle layers within the preimplanted urinary bladder were disorganized (C, arrowheads). The proportion of smooth muscle layer area in the shamirradiated urinary bladders (B, arrows) was clearly higher than that in the preimplanted group $(\mathrm{D}$, arrowheads). (A, C): Hematoxylin and eosin (HE) stain. (B, D): Masson trichrome stain. (E, F) The proportion of the nerve fiber area in the sham-irradiated urinary bladders ( $E$, arrows) was also clearly higher than that in the preimplanted ones (F, arrowheads). Acethylcholinesterase antibody stain. $(G, H)$ Collagen fibers of the shamirradiated urinary bladders were located among the smooth muscle layers ( $G$, red, arrows), and the smooth muscle cells within the layers were negative for P4HB (G, inset; blue: nuclei, Scale bar: $20 \mu \mathrm{m}$ ).

However, the collagen fibers of the preimplanted urinary bladders were largely absent except where they were accumulated together in clusters ( $\mathbf{H}$, red, arrowheads). The remaining smooth muscle cells expressed $\mathrm{P} 4 \mathrm{HB}$ $(\mathbf{H}$, inset green; blue: nuclei, Scale bar: $20 \mu \mathrm{m})$. Picrosirious red stain. All images were from the same regions in serial sections with the exterior surface of the urinary bladder to the left and the luminal surface to the right. Scale bar: $100 \mu \mathrm{m}$.
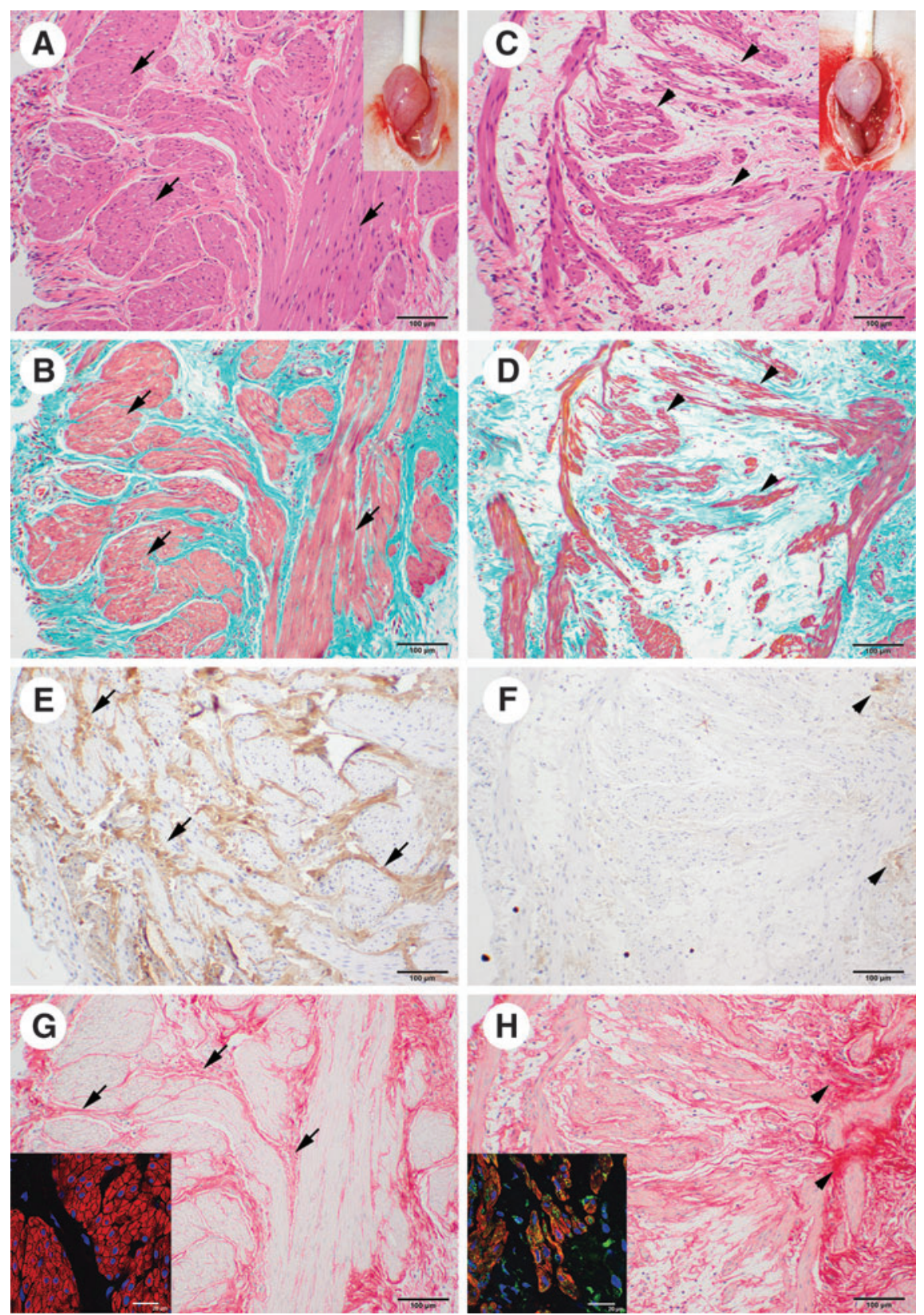

control urinary bladders had a few nerve fibers that were positively stained for acethylcholinesterase (Fig. 3E). In contrast, the cell-implanted urinary bladders had a greater number of acethylcholinesterase-positive nerve fibers (Fig. $3 F)$ that occupied a significantly greater proportion of the observed fields, $0.09 \pm 0.01$, than that in the control urinary bladders, $0.01 \pm 0.003(p<0.01$, Table 1$)$. The proportions of smooth muscle and nerve fiber areas in the cell-implanted urinary bladders were the same as those in the shamirradiated ones (Table 1).

Four weeks after the cell-free injection, the distribution of collagen fibers was similar to that in the preimplantation bladder. Thus, the collagen fibers were largely absent, except where they were accumulated together in clusters (Fig. 3G). Similar to the preimplantation urinary bladders, the remaining smooth muscle cells expressed P4HB (Fig. 3G inset). In contrast, collagen fibers of the cell-implanted urinary bladders were distributed among the reconstructed smooth muscle layers (Fig. 3H), and fewer of those cells expressed P4HB (Fig. 3H inset) compared with the cell-free injected control and preimplanted groups.

\section{Differentiation of bone marrow-derived cells into smooth muscle and nerve cells}

Fourteen days after implantation, the donor cells were identified in the urinary bladders by the presence of GFP (Fig. 4A-C). Some GFP-positive implanted cells were positive for SMA, desmin, or calponin I (Fig. 4D-F, respectively). These double-positive cells showed that the implanted cells differentiated into smooth musclelike cells (Fig. 4G-I, respectively). Similarly, some GFPpositive implanted cells (Fig. 5A-C) were positive for S100, tubulin beta 3 , or CGRP (Fig. 5D-F, respectively). 
Table 1. Proportions of Smooth Muscle Layers and Nerve Fiber Areas

\begin{tabular}{lcccc}
\hline & $\begin{array}{c}\text { Un-irradiated } \\
\text { sham }\end{array}$ & $\begin{array}{c}\text { Irradiated } \\
\text { preimplantation }\end{array}$ & $\begin{array}{c}\text { Irradiated } \\
\text { cell-free control }\end{array}$ & $\begin{array}{c}\text { Irradiated cell } \\
\text { implantation }\end{array}$ \\
\hline Smooth muscle layer & $0.20 \pm 0.01$ & $0.08 \pm 0.01^{\mathrm{a}}$ & $0.11 \pm 0.004$ & $0.19 \pm 0.01^{\mathrm{b}}$ \\
Nerve fiber & $0.12 \pm 0.03$ & $0.03 \pm 0.01^{\mathrm{c}}$ & $0.01 \pm 0.003$ & $0.09 \pm 0.01^{\mathrm{d}}$ \\
\hline
\end{tabular}

${ }^{\mathrm{a}} p<0.05,{ }^{c} p<0.01$; compared with the un-irradiated sham group.

${ }^{\mathrm{b}} p<0.05, \mathrm{~d}_{p}<0.01$; compared with the cell-free control group.

These double-positive cells showed that the implanted cells differentiated into nerve-like cells (Fig. 5G-I, respectively). Both the newly differentiated smooth muscleand nerve-like cells were organized into reconstructed tissues.

\section{Improved bladder functions after implantation of bone marrow-derived cells}

In cystometric investigations, the sham-irradiated rats showed typical micturition patterns, including voiding, at
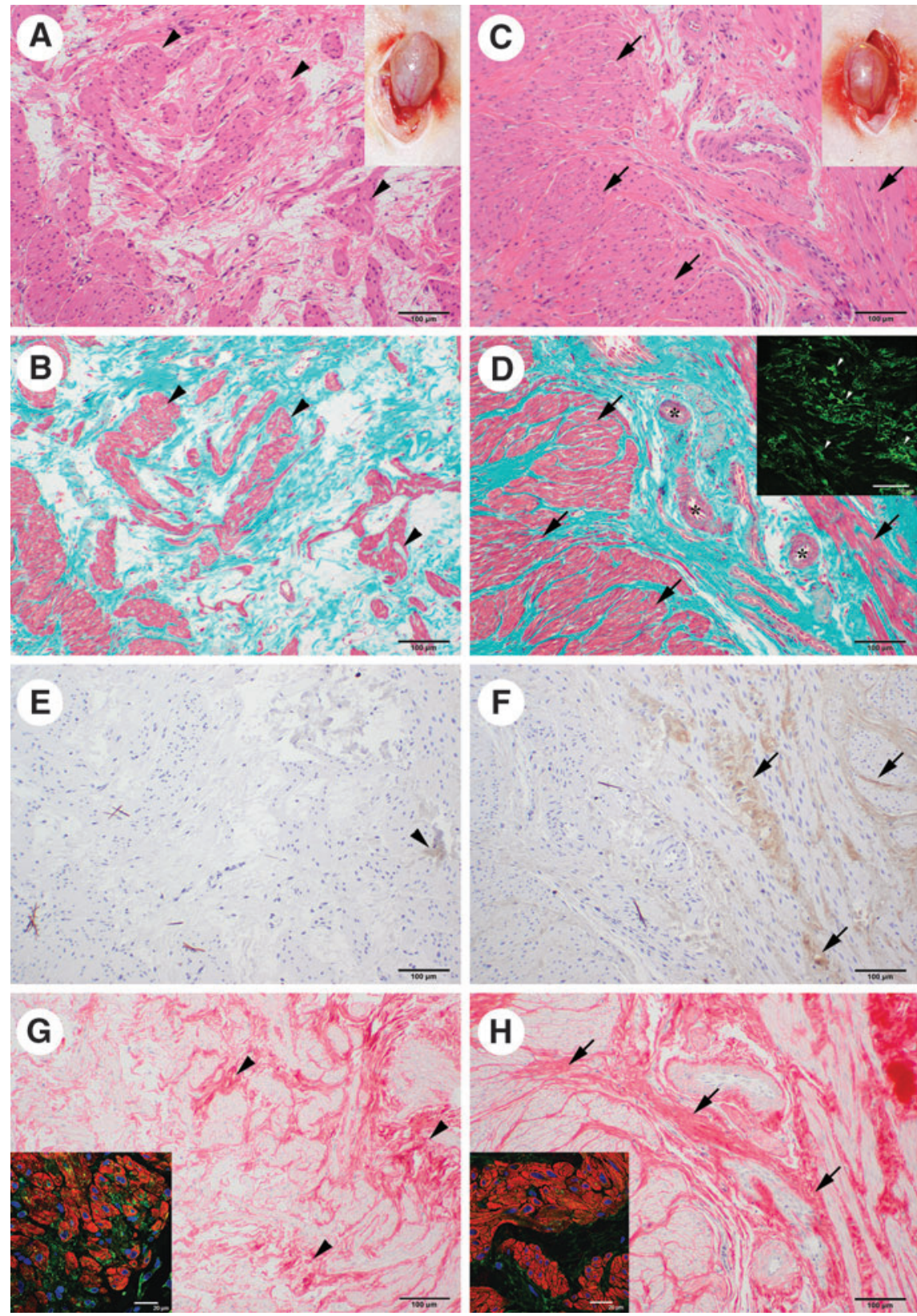
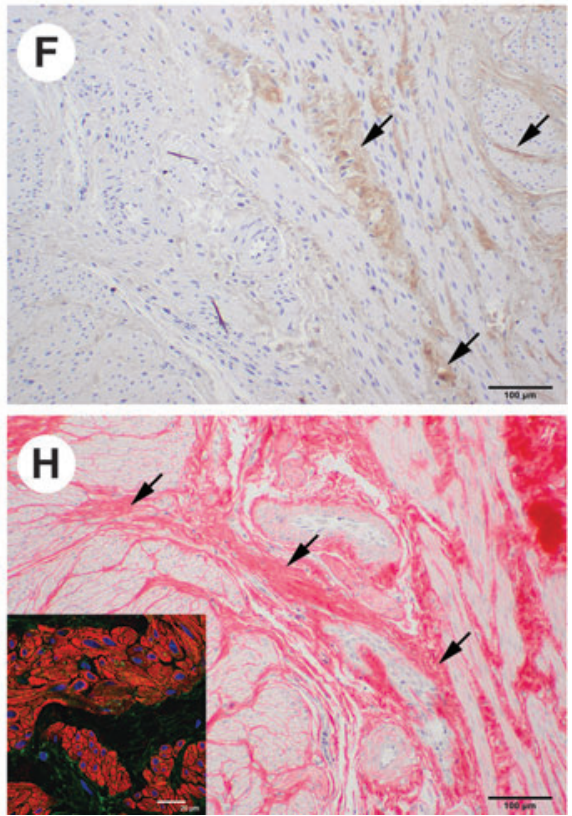

FIG. 3. Reconstruction of bladder tissues in the cell-implanted urinary bladders. (A-D) The gross appearance of the cell-free control-injected bladder walls was similar to that in the preimplanted group (A, inset); however, the cell-implanted bladder walls had distinct blood vessels ( $C$, inset). The control urinary bladders had a few typical smooth muscle layers (A, B, arrowheads). The cell-implanted urinary bladders had thick and typical smooth muscle layers composed of numerous smooth muscle cells (C, D, arrows). In addition, there were some blood vessels (D, asterisks). The cellimplanted urinary bladders had GFPpositive donor cells $(D$, inset, white arrowheads, Scale bar: $50 \mu \mathrm{m})$. (A, C): HE stain, (B, D): Masson trichrome stain. (E, F) The control urinary bladders had a few nerve fibers that were positive for acethylcholinesterase $(\mathrm{E}$, arrowhead). The cell-implanted urinary bladders had more abundant nerve fibers ( $\mathrm{F}$, arrows). Acethylcholinesterase antibody stain. (G, H) The distribution of collagen fibers in the control urinary bladders was similar to that in the irradiated preimplanted urinary bladders ( $G$, arrowheads), and the remaining smooth muscle also strongly expressed $\mathrm{P} 4 \mathrm{HB}$ (G, inset green, blue: nuclei, Scale bar: $20 \mu \mathrm{m})$. The collagen fibers of the cellimplanted urinary bladders were placed among the reconstructed smooth muscle layers ( $\mathbf{H}$, arrows), and the expression level of $\mathrm{P} 4 \mathrm{HB}$ decreased $(\mathbf{H}$, inset green, blue: nuclei, Scale bar: $20 \mu \mathrm{m})$. Picrosirious red stain. All images were from the same regions in serial sections with the exterior surface of the urinary bladder to the left and the luminal surface to the right. Scale bar: $100 \mu \mathrm{m}$. 
FIG. 4. Differentiation of bone marrow-derived cells into smooth muscle-like cells. The implanted cells were identifiable by the presence of GFP (A-C, green, arrows). The GFP-positive cells were simultaneously positive for SMA (D), desmin (E), or calponin I (F), all of which are differentiation markers of smooth muscle cells (red, arrows). These doublepositive cells (G-I, yellow, arrows) showed that the implanted cells differentiated into smooth muscle-like cells. Blue: nuclei.

FIG. 5. Differentiation of bone marrow-derived cells into nervelike cells. Some GFP-positive implanted cells (A-C, green, arrows) were positive for S100 (D), tubulin beta $3(\mathrm{E})$, or calcitonin generelated peptide $(\mathbf{F})$, all of which are differentiation markers for nerve cell (red, arrows). These double-positive cells showed that the implanted cells differentiated into nerve-like cells (G-I, yellow, arrows). Blue: nuclei.
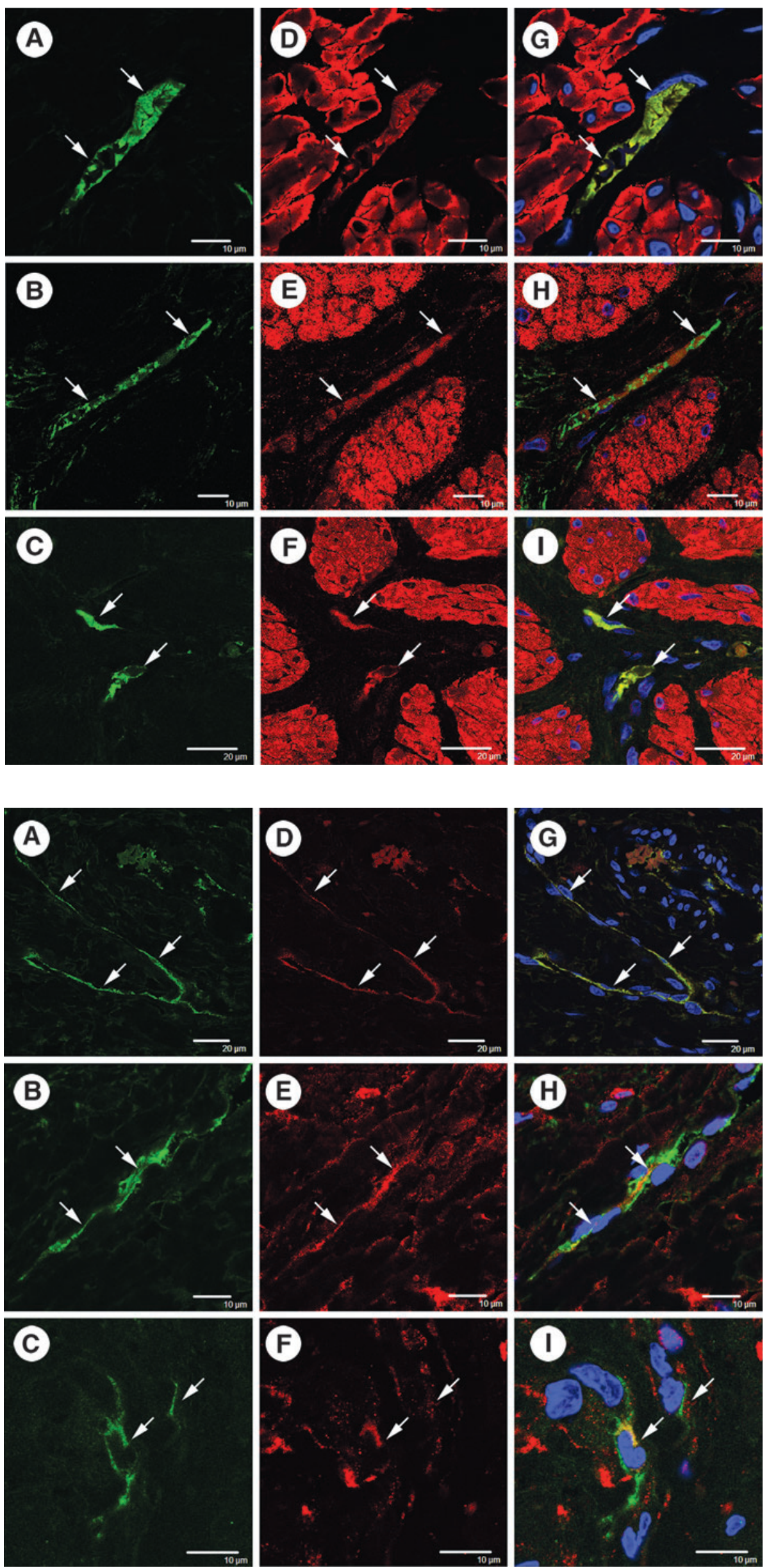
regular intervals of about $5 \mathrm{~min}$ and micturition volumes of about $1 \mathrm{~mL}$ (Fig. 6A). In contrast, the patterns of the preimplanted irradiated rats were irregularly prolonged (Fig. $6 \mathrm{~B})$. The basal, threshold, and micturition pressures and the micturition volume of the preimplanted rats did not differ significantly compared with the sham-irradiated rats (Table 2). The voiding interval of the preimplanted rats, $7.92 \pm 1.09 \mathrm{~min}$, was significantly longer than that of the sham-irradiated ones, $5.50 \pm 0.43 \mathrm{~min}(p<0.01$, Table 2$)$. The residual volume of the preimplanted rats, $0.13 \pm 0.03 \mathrm{~mL}$, was significantly higher than that of the sham-irradiated ones, $0.05 \pm 0.01 \mathrm{~mL}(p<0.05$, Table 2$)$.

Four weeks after the cell-free injection, the micturition patterns of the cell-free injected control group (Fig. 6C) remained similar to those in the preimplanted irradiated rats (Fig. 6B). In contrast, the cell-implanted rats showed micturition patterns (Fig. 6D) that were similar to those in the sham-irradiated rats (Fig. 6A). The basal, threshold, and micturition pressures and the micturition volume of the cellimplanted rats were similar to those in the sham-irradiated rats (Table 2). Further, the voiding interval of the cell-implanted rats was regular (Fig. 6D), and the value, $5.46 \pm 0.33 \mathrm{~min}$, was similar to that in the sham-irradiated rats (Table 2). The voiding interval was significantly reduced compared with the preimplantation group $(p<0.05)$ and the cell-free injected control group, $7.39 \pm 0.54 \mathrm{~min}(p<0.01$, Table 2). The residual volume of the cell-implanted rats, $0.04 \pm 0.01 \mathrm{~mL}$, was significantly lower than that of the cellfree injected control group, $0.15 \pm 0.05 \mathrm{~mL}(p<0.05$, Table 2$)$.

\section{Discussion}

In this study, we developed a radiation-injured urinary bladder model in rats that investigates the potential of bone marrow-derived cells to regenerate bladder tissues and restore function. Irradiated urinary bladders in animal models undergo pathological changes in three phases..$^{25}$ The first phase is the acute damage consisting of urothelial swelling, ulceration, and vascular endothelial cell damage. ${ }^{26,27}$ The second phase is the infiltration of inflammatory cells. ${ }^{26-28}$ The third phase is chronic and is associated with collagen deposition and developing fibrosis. ${ }^{26,27,29}$ Some studies reported that animal urinary bladder damage induced by a single dose of radiation had pathological changes that included epithelial denudation and focal hyperplasia with ulceration, ${ }^{26}$ changes in axon profiles and mast cell density, ${ }^{27}$ and increased formation of superoxide free radicals. ${ }^{25}$ In addition, hydronephrosis often occurred with radiationinduced dysuria. ${ }^{30}$

In the present study, we conducted repeated irradiations to achieve a final dose of $10 \mathrm{~Gy}$, after which there was a 2-week rest period before cell implantation. Higher doses of approximately $70 \mathrm{~Gy}$, a dose range commonly used for pelvic radiotherapy, caused an unacceptable decrease of more than $10 \%$ in the body weight or even death of the exposed animal. While our dose was lower than clinically therapeutic levels, this model showed significant decreases in smooth muscle and nerve fiber areas in the urinary bladders. Furthermore, the remaining muscle cells showed a high expression level of $\mathrm{P} 4 \mathrm{HB}$, which generally indicates the development of fibrosis. ${ }^{31}$ However, as observed by light microscopy, the urothelium did not appear to be seriously damaged, and the kidneys did not have hydronephrosis (data not shown). In contrast, just after final irradiation, the apparent damage to the urinary bladders just described was highly variable (data not shown). We found that during the 2-week rest period, the damage in the urinary bladders became more uniform, thus providing a high-quality model.

In irradiated urinary bladder models, acute bladder dysfunctions included decreased bladder capacity, increased micturition frequency, and dysuria. ${ }^{23,25,26}$ Chronic bladder dysfunctions included decreases of bladder compliance and contraction involving fibrosis. ${ }^{23,26,27}$ In cystometric investigations of our radiation-injured model, the basal, threshold, and micturition pressures, and the micturition volume did not change compared with the sham-irradiated normal rats. These findings might suggest that the remaining tissue components retained some bladder functions. However, the voiding interval was irregularly prolonged, and the residual volume was significantly increased. This study was not designed to determine whether more serious radiation-induced bladder dysfunctions developed during a longer postradiation period. The 4-week postimplantation follow-up period also minimized the potentially complicating factor of aging that might occur in a longer-term study. Nevertheless, the findings suggest that without the intervention of implanted bone marrow-derived cells, our radiation-injured urinary bladder model might be in the process of developing pathological damage that is characteristic of chronic bladder dysfunctions.

Four weeks after the implantation of the bone marrowderived cells, the urinary bladders recovered tissue structures and functions that were similar to healthy rats. The cell-free control-injected urinary bladders had small areas composed of several smooth muscle cells that did not form typical smooth muscle layers. The residual volumes of these control urinary bladders remained the same as those in the radiation-injured, preimplanted group. In contrast, the cellimplanted urinary bladders developed reconstructed smooth muscle layers composed of numerous smooth muscle cells. The proportion of the smooth muscle layer area in the cellimplanted urinary bladders was significantly higher than that in the cell-free injected control group. Thus, the reconstructed smooth muscle layers are probably responsible for the decrease in residual volume.

Similarly, the cell-implanted urinary bladders recovered nerve fibers with a relative area significantly higher than that of the cell-free injected control urinary bladders. The voiding interval of the cell-implanted rats was similar to healthy rats, which were regular and of a shorter duration than those of the preimplanted and cell-free injected control ones. While we could not determine whether the recovered nerve fibers were afferent or efferent in nature, it is likely that their presence was related to the recovery of the regular and normal voiding interval.

The presence of bone marrow-derived cells in the injured bladders likely promoted the recovery by three different mechanisms. First, the implanted bone marrow-derived cells were able to differentiate into smooth muscle- and nerve-like cells within the irradiated urinary bladders. Earlier, we had shown that the bone marrow-derived cells have the potential to differentiate into various cells within freeze-injured lower urinary tracts. ${ }^{24,32}$ The present study also showed that some implanted GFP-positive cells expressed not only SMA, but 

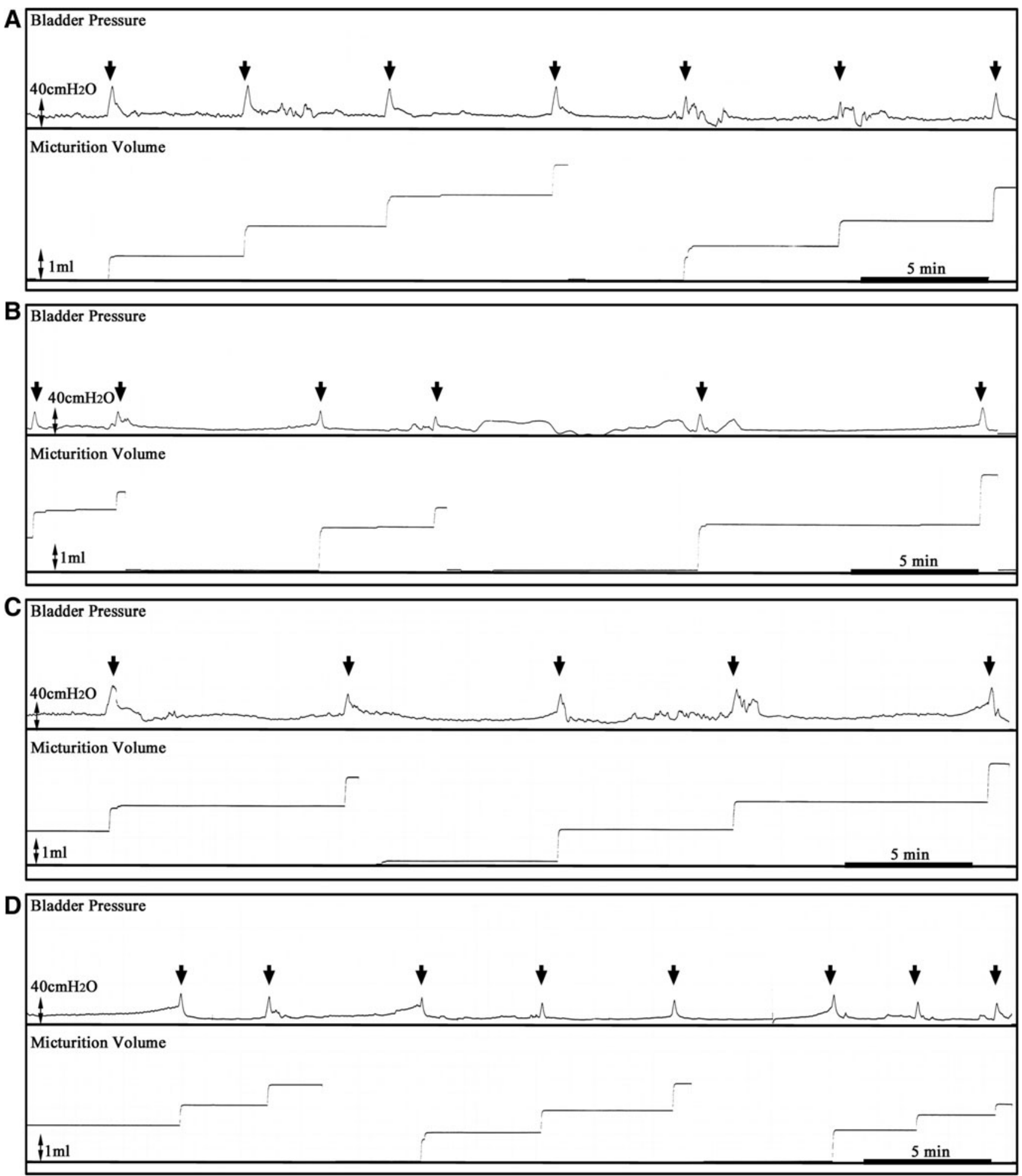

FIG. 6. Typical micturition patterns in each group. (A) The sham-irradiated group showed a regular micturition pattern. (B) The micturition patterns of the preimplanted rats were irregular with longer intervals between micturition periods. (C) The micturition patterns of the 4-week cell-free control group were similar to those in the preimplantation rats. (D) The 4-week cell-implantation group showed regular micturition patterns that were similar to those in the sham-irradiated rats.

also desmin and calponin I, which are usually expressed at later stages than SMA during smooth muscle cell development. ${ }^{33-38}$ Other GFP-positive cells expressed S100 and tubulin beta 3, which are common nerve cell markers, as well as CGRP, which is expressed in afferent nerve cells. There- fore, the implanted GFP-positive cells differentiated into smooth muscle- and nerve-like cells. These differentiated cells then became organized into the reconstructed tissues.

The second way in which the implanted cells could have facilitated recovery is that they might promote the growth or 
Table 2. Cystometric Investigation of Bladder Functions

\begin{tabular}{lcccc}
\hline & $\begin{array}{c}\text { Un-irradiated } \\
\text { sham }\end{array}$ & $\begin{array}{c}\text { Irradiated } \\
\text { preimplantation }\end{array}$ & $\begin{array}{c}\text { Irradiated } \\
\text { cell-free control }\end{array}$ & $\begin{array}{c}\text { Irradiated } \\
\text { cell-implantation }\end{array}$ \\
\hline Basal pressure $\left(\mathrm{cmH}_{2} \mathrm{O}\right)$ & $13.70 \pm 2.02$ & $11.56 \pm 1.82$ & $15.73 \pm 2.78$ & $17.67 \pm 3.20$ \\
Threshold pressure $\left(\mathrm{cmH}_{2} \mathrm{O}\right)$ & $26.62 \pm 2.86$ & $24.38 \pm 3.67$ & $29.91 \pm 4.51$ & $32.82 \pm 6.82$ \\
Micturition pressure $\left(\mathrm{cmH}_{2} \mathrm{O}\right)$ & $48.34 \pm 4.20$ & $51.75 \pm 5.18$ & $54.99 \pm 6.07$ & $53.49 \pm 6.70$ \\
Micturition volume $(\mathrm{mL})$ & $0.92 \pm 0.07$ & $1.21 \pm 0.17$ & $1.10 \pm 0.11$ & $0.92 \pm 0.06$ \\
Voiding interval $(\mathrm{min})$ & $5.50 \pm 0.43$ & $7.92 \pm 1.09^{\mathrm{a}}$ & $7.39 \pm 0.54$ & $5.46 \pm 0.33^{\mathrm{b}, \mathrm{c}}$ \\
Residual volume $(\mathrm{mL})$ & $0.05 \pm 0.01$ & $0.13 \pm 0.03^{\mathrm{d}}$ & $0.15 \pm 0.05$ & $0.04 \pm 0.01^{\mathrm{e}}$ \\
\hline
\end{tabular}

${ }^{\mathrm{a}} p<0.01,{ }^{\mathrm{d}} p<0.05$; compared with the un-irradiated sham group.

${ }^{\mathrm{b}} p<0.05$; compared with the irradiated preimplantation group.

${ }^{c} p<0.01,{ }^{e} p<0.05$; compared with the irradiated cell-free control group.

development of the remaining host cells that were not damaged by the radiation. Bone marrow-derived cells are well known to promote the natural healing of remaining cells within the damaged tissues. ${ }^{39-41}$ Similarly, in this study, the cell-implanted urinary bladders showed that typical bladder tissues, including some blood vessel structures, were formed with the host cells.

The third effect that may be attributed to the implanted cells is that the urinary bladders showed a decrease in the number of smooth muscle cells expressing $\mathrm{P} 4 \mathrm{HB}$ compared with the cell-free implanted controls. The decrease in the $\mathrm{P} 4 \mathrm{HB}$ expression level might indicate the inhibition of fibrosis development, as occurs with bone marrow-derived cell-seeded patches in sheep. ${ }^{42}$ Therefore, the implanted bone marrow-derived cells promote not only reconstruction of the smooth muscle layers and nerve fibers, but they may also have other as yet unknown effects that facilitate recovery in damaged urinary bladders.

We have reported that the potential development of the bone marrow-derived cells depends on the microenvironment within the recipient damaged tissues. ${ }^{43}$ We do not yet know whether the urinary bladders that are damaged due to clinical radiotherapy have a suitable microenvironment for bone marrow-derived cell growth and differentiation. A further clinical complication is that radiotherapy often induces more serious damage, including loss of bladder tissues, bladder shrinkage with fibrosis, and synechia between urinary bladders and intestines. ${ }^{1,12,17,19,20}$ For these severe cases, treatment would require a combination of scaffolds, such as a bio-matrix and/or growth factors that support the implanted cells. The present study, at least, showed that the implantation of bone marrow-derived cells has the potential to recover the radiotherapy-induced bladder dysfunctions before more severe damage occurs.

After 4 weeks, the body weight of the cell-implanted rats significantly increased compared with that of the cell-free control rats. Changes in the body weight depend on the conditions of the whole animal. Thus, our histological analysis and bladder function measurements are not sufficient to explain the increase in body weight. However, the improved bladder functions, as a component of whole body health, might be partially responsible for the increase in body weight.

In conclusion, the bone marrow-derived cells implanted into radiation-injured rat urinary bladders reconstructed smooth muscle layers and nerve fibers. Some of the im- planted cells differentiated into smooth muscle- or nerve-like cells and became organized into the reconstructed tissues. The cell-implanted urinary bladders re-acquired regular voiding intervals and low residual volume, similar to the normal urinary bladders. Therefore, the implantation of bone marrow-derived cells has great potential in the treatment for radiotherapy-induced bladder dysfunctions.

\section{Acknowledgments}

This study was supported by a Grant-in-Aid for Scientific Research from the Japanese Ministry of Education, Culture, Sport, Science, and Technology (no. 22791471 and 21592069), and by a Grant-in-Aid for Terumo Life Science Foundation in Japan (2011).

\section{Disclosure Statement}

No competing financial interests exist.

\section{References}

1. Incrocci, L. Sexual function after external-beam radiotherapy for prostate cancer: what do we know? Crit Rev Oncol Hematol 57, 165, 2006.

2. Kimura, M., Yan, H., Rabbani, Z., Satoh, T., Baba, S., Yin, F.F., Polascik, T.J., Donatucci, C.F., Vujaskovic, Z., and Koontz, B.F. Radiation-induced erectile dysfunction using prostate-confined modern radiotherapy in a rat model. J Sex Med 8, 2215, 2011.

3. Siglin, J., Kubicek, G.J., Leiby, B., and Valicenti, R.K. Time of decline in sexual function after external beam radiotherapy for prostate cancer. Int J Radiat Oncol Biol Phys 76, 31, 2010.

4. van der Wielen, G.J., Mulhall, J.P., and Incrocci, L. Erectile dysfunction after radiotherapy for prostate cancer and radiation dose to the penile structures: a critical review. Radiother Oncol 84, 107, 2007.

5. Fallon, B., Loening, S., Hawtrey, C.E., Lifshitz, S.G., and Buchsbaum, H.J. Urologic complications of pelvic exenteration for gynecologic malignancy. J Urol 122, 158, 1979.

6. Fulmer, B.R., Bissonette, E.A., Petroni, G.R., and Theodorescu, D. Prospective assessment of voiding and sexual function after treatment for localized prostate carcinoma: comparison of radical prostatectomy to hormonobrachytherapy with and without external beam radiotherapy. Cancer 91, 2046, 2001.

7. Oda, Y., Todo, Y., Hanley, S., Hosaka, M., Takeda, M., Watari, H., Kaneuchi, M., Kudo, M., and Sakuragi, N. Risk 
factors for persistent low bladder compliance after radical hysterectomy. Int J Gynecol Cancer 21, 167, 2011.

8. Rosewall, T., Catton, C., Currie, G., Bayley, A., Chung, P., Wheat, J., and Milosevic, M. The relationship between external beam radiotherapy dose and chronic urinary dysfunction-a methodological critique. Radiother Oncol 97, 40, 2010.

9. Sanchiz, F., Milla, A., Artola, N., Julia, J.C., Moya, L.M., Pedro, A., and Vila, A. Prevention of radioinduced cystitis by orgotein: a randomized study. Anticancer Res 16, 2025, 1996.

10. Beard, C.J. The risk of bladder, bowel, and sexual dysfunction after radiation therapy: what the data tell us and how we can use it to counsel our patients. Cancer J 11, 106, 2005.

11. Hanlon, A.L., Watkins Bruner, D., Peter, R., and Hanks, G.E. Quality of life study in prostate cancer patients treated with three-dimensional conformal radiation therapy: comparing late bowel and bladder quality of life symptoms to that of the normal population. Int J Radiat Oncol Biol Phys 49, 51, 2001.

12. Schellhammer, P.F., Jordan, G.H., and el-Mahdi, A.M. Pelvic complications after interstitial and external beam irradiation of urologic and gynecologic malignancy. World J Surg 10, 259, 1986

13. Fiorino, C., Valdagni, R., Rancati, T., and Sanguineti, G. Dose-volume effects for normal tissues in external radiotherapy: pelvis. Radiother Oncol 93, 153, 2009.

14. Jeggo, P.A. Risks from low dose/dose rate radiation: what an understanding of DNA damage response mechanisms can tell us. Health Phys 97, 416, 2009.

15. Ling, C.C., Kutcher, G.J., and Mohan, R. Understanding radiation damage in late effect normal tissues: learning to negotiate the dose-volume-complication terrain or waiting for Godot? Int J Radiat Oncol Biol Phys 31, 1357, 1995.

16. Nave, C., and Garman, E.F. Towards an understanding of radiation damage in cryocooled macromolecular crystals. J Synchrotron Radiat 12, 257, 2005.

17. Denton, A.S., Andreyev, H.J., Forbes, A., and Maher, E.J. Systematic review for non-surgical interventions for the management of late radiation proctitis. Br J Cancer 87, 134, 2002.

18. Marks, L.B., Carroll, P.R., Dugan, T.C., and Anscher, M.S. The response of the urinary bladder, urethra, and ureter to radiation and chemotherapy. Int J Radiat Oncol Biol Phys 31, 1257, 1995.

19. Cheng, C., and Foo, K.T. Management of severe chronic radiation cystitis. Ann Acad Med Singapore 21, 368, 1992.

20. Smit, S.G., and Heyns, C.F. Management of radiation cystitis. Nat Rev Urol 7, 206, 2010.

21. Greenberger, J.S., Epperly, M.W., Gretton, J., Jefferson, M., Nie, S., Bernarding, M., Kagan, V., and Guo, H.L. Radioprotective gene therapy. Curr Gene Ther 3, 183, 2003.

22. Kawakami, M., Igawa, Y., Inoue, H., Koizumi, K., and Nishizawa, O. Rupture of urachal diverticulum in radiation cystitis and neurogenic bladder dysfunction after radical hysterectomy. Int J Urol 11, 919, 2004.

23. Soler, R., Vianello, A., Fullhase, C., Wang, Z., Atala, A., Soker, S., Yoo, J.J., and Koudywilliam, J. Vascular therapy for radiation cystitis. Neurourol Urodyn 30, 428, 2011.

24. Imamura, T., Kinebuchi, Y., Ishizuka, O., Seki, S., Igawa, Y., and Nishizawa, $\mathrm{O}$. Implanted mouse bone marrow-derived cells reconstruct layered smooth muscle structures in injured urinary bladders. Cell Transplant 17, 267, 2008.

25. Kanai, A.J., Zeidel, M.L., Lavelle, J.P., Greenberger, J.S., Birder, L.A., de Groat, W.C., Apodaca, G.L., Meyers, S.A.,
Ramage, R., and Epperly, M.W. Manganese superoxide dismutase gene therapy protects against irradiation-induced cystitis. Am J Physiol Renal Physiol 283, F1304, 2002.

26. Stewart, F.A., Lundbeck, F., Oussoren, Y., and Luts, A. Acute and late radiation damage in mouse bladder: a comparison of urination frequency and cystometry. Int J Radiat Oncol Biol Phys 21, 1211, 1991.

27. Vale, J.A., Bowsher, W.G., Liu, K., Tomlinson, A., Whitfield, H.N., and Trott, K.R. Post-irradiation bladder dysfunction: development of a rat model. Urol Res 21, 383, 1993.

28. Antonakopoulos, G.N., Hicks, R.M., and Berry, R.J. The subcellular basis of damage to the human urinary bladder induced by irradiation. J Pathol 143, 103, 1984.

29. Dorr, W., and Bentzen, S.M. Late functional response of mouse urinary bladder to fractionated X-irradiation. Int J Radiat Biol 75, 1307, 1999.

30. Knowles, J.F. Radiation-induced hydronephrosis in the rat: a new experimental model. Int J Radiat Biol Relat Stud Phys Chem Med 48, 737, 1985.

31. Zion, O., Genin, O., Kawada, N., Yoshizato, K., Roffe, S., Nagler, A., Iovanna, J.L., Halevy, O., and Pines, M. Inhibition of transforming growth factor beta signaling by halofuginone as a modality for pancreas fibrosis prevention. Pancreas 38, 427, 2009.

32. Imamura, T., Ishizuka, O., Kinebuchi, Y., Kurizaki, Y., Nakayama, T., Ishikawa, M., and Nishizawa, O. Implantation of autologous bone-marrow-derived cells reconstructs functional urethral sphincters in rabbits. Tissue Eng Part A 17, 1069, 2011.

33. Frid, M.G., Shekhonin, B.V., Koteliansky, V.E., and Glukhova, M.A. Phenotypic changes of human smooth muscle cells during development: late expression of heavy caldesmon and calponin. Dev Biol 153, 185, 1992.

34. Hautmann, M.B., Adam, P.J., and Owens, G.K. Similarities and differences in smooth muscle alpha-actin induction by TGF-beta in smooth muscle versus non-smooth muscle cells. Arterioscler Thromb Vasc Biol 19, 2049, 1999.

35. Hungerford, J.E., Owens, G.K., Argraves, W.S., and Little, C.D. Development of the aortic vessel wall as defined by vascular smooth muscle and extracellular matrix markers. Dev Biol 178, 375, 1996.

36. Li, L., Liu, Z., Mercer, B., Overbeek, P., and Olson, E.N. Evidence for serum response factor-mediated regulatory networks governing SM22alpha transcription in smooth, skeletal, and cardiac muscle cells. Dev Biol 187, 311, 1997.

37. Owens, G.K. Regulation of differentiation of vascular smooth muscle cells. Physiol Rev 75, 487, 1995.

38. Ya, J., Markman, M.W., Wagenaar, G.T., Blommaart, P.J., Moorman, A.F., and Lamers, W.H. Expression of the smooth-muscle proteins alpha-smooth-muscle actin and calponin, and of the intermediate filament protein desmin are parameters of cardiomyocyte maturation in the prenatal rat heart. Anat Rec 249, 495, 1997.

39. Crisostomo, P.R., Wang, Y., Markel, T.A., Wang, M., Lahm, T., and Meldrum, D.R. Human mesenchymal stem cells stimulated by TNF-alpha, LPS, or hypoxia produce growth factors by an NF kappa B- but not JNK-dependent mechanism. Am J Physiol Cell Physiol 294, C675, 2008.

40. Fiorina, P., Pietramaggiori, G., Scherer, S.S., Jurewicz, M., Mathews, J.C., Vergani, A., Thomas, G., Orsenigo, E., Staudacher, C., La Rosa, S., Capella, C., Carothers, A., Zerwes, H.G., Luzi, L., Abdi, R., and Orgill, D.P. The mobilization and effect of endogenous bone marrow progenitor cells in diabetic wound healing. Cell Transplant 19, 1369, 2010. 
41. Nishida, T., Tsuji, S., Tsujii, M., Ishii, S., Yoshio, T., Shinzaki, S., Egawa, S., Irie, T., Kakiuchi, Y., Yasumaru, M., Iijima, H., Tsutsui, S., Kawano, S., and Hayashi, N. Cultured bone marrow cell local implantation accelerates healing of ulcers in mice. J Gastroenterol 43, 124, 2008.

42. Mendelson, K., Aikawa, E., Mettler, B.A., Sales, V., Martin, D., Mayer, J.E., and Schoen, F.J. Healing and remodeling of bioengineered pulmonary artery patches implanted in sheep. Cardiovasc Pathol 16, 277, 2007.

43. Imamura, T., Yamamoto, T., Ishizuka, O., Gotoh, M., and Nishizawa, $\mathrm{O}$. The microenvironment of freeze-injured mouse urinary bladders enables successful tissue engineering. Tissue Eng Part A 15, 3367, 2009.
Address correspondence to: Tetsuya Imamura, Ph.D. Department of Lower Urinary Tract Medicine Shinshu University School of Medicine 3-1-1 Asahi, Matsumoto Nagano 390-8621 Japan

E-mail: imatetu@shinshu-u.ac.jp

Received: February 1, 2012 Accepted: April 3, 2012

Online Publication Date: May 14, 2012 